\title{
Canadian Society for Renaissance Studies Report on Annual General Meeting, 24 May 1981, Halifax, N.S.
}

\section{Report of the Secretary-Treasurer (K.R. Bartlett):}

The current balance of funds, including the SSHRC travel grant, amounts to $\$ 8,021.77$. The Society's dues to the Canadian Federation for the Humanities totalled $\$ 333.00$ this year and total disbursements on supplies (including postage, typing, photocopying and telephone) were \$181.35.

The membership of the Society was analysed by the Secretary-Treasurer. As of 19 May 1981 there were 94 members in good standing (10 additional members have since joined, bringing the total to 104) of whom 63 subscribed to Renaissance and Reformation through the C.S.R.S. The regional distribution indicates that half of the membership comes from Ontario, and 15 members each from Québec and the Prairies. There are 8 members in the Atlantic Provinces and 4 in B.C. Similarly, there is a heavy concentration of members in English and French (55), indicating not only the interest of those disciplines in the Renaissance but also the placing of the C.S.R.S. together with literary societies in the Learneds programme.

Editor's Report, Renaissance and Reformation/Renaissance et Réforme (Richard Van Fossen):

The editor noted that the problems of the past in keeping up-to-date mailing lists and acting on subscription requests have been largely solved. A computerized subscription list has been implemented. The journal has moved to four issues per year.

F. David Hoeniger added that the Editor and his business assistant merited our appreciation for the increased efficiency of the journal.

\section{President's Report (Elaine Limbrick):}

The President observed how hectic the year had been since she had functioned as Programme Chairman for the meeting as well. Also, she suggested that interested members request the I.R.I.S. newsletter from Professor R. Ortali at Suny Binghamton and pay special attention to the visits of eminent Renaissance scholars to North America so that as many centres as possible may benefit from such opportunities.

As promised, the President has been attempting to strengthen international contacts for the C.S.R.S. She has contacted the Seizièmistes in France, the Warburg Institute and University College, London. Also, mention was made of the international meeting of Neo-Latinists at St. Andrews, Scotland, later in the year. 
The proposal to publish a directory of Renaissance Scholars in Canada was introduced. Only those who are members of the C.S.R.S. would appear and thus there might be a further impetus for all active Renaissance Scholars to join the Society. The material to appear in the directory would include the individual's name, university, discipline, current research activities and previous publications. A member suggested that a cross-referenced index might be added if the directory were to be organised alphabetically by name. It was moved that the executive be empowered to produce such a directory. An amendment to the motion was accepted by the mover and seconder to include the phrase "after consulting with individual members." The motion, as amended, was carried. .

Elaine Limbrick then introduced the revised administrative grant formula recommended by the C.F.H. The present structure was seen as inequitable, so under the proposed schedule each society would receive a base grant of $\$ 500.00$ together with $\$ 10.34$ per member. There would be a 3-year period during which those societies getting overly large grants would have them adjusted to conform to the new formula. The C.S.R.S. would benefit considerably from the new dispensation.

The President strongly recommended support for the C.F.H. proposal which must pass by a $2 / 3$ vote of the membership. The new schedule would permit the Society to plan for the future and provide an adequate administrative budget. Peter Bietenholz asked if this new arrangement would result in a proliferation of new, small societies. The President responded that the procedures in place for admitting new societies into the C.F.H. would preclude such a proliferation.

It was moved and seconded that the C.S.R.S. accept the new formula as proposed by the C.F.H. The motion was carried unanimously.

\section{The Nominating Committee, 1982:}

The Chairman introduced a proposal to bring the nominating committee of the C.S.R.S. into line with other societies. She suggested the following amendment: the nominating committee should consist of the Past President, the Current President, plus one member-at-large. A motion to this effect was carried.

Egmont Lee then proposed a notice of motion to amend the by-laws of the Society in order that the local representative for the annual meeting might be part of the executive as a member-at-large and hold office for only one year. This was a notice of motion only because of the requirement that any motion to change the constitution be introduced six weeks prior to the vote.

A lengthy discussion ensued in which it was suggested that the responsibilities of the local representative and the programme chairman be divided and that a regular two-year tenure of office might be useful for such individuals. Ultimately, it was suggested that the question be decided by the executive on an ad hoc basis annually through the co-option into the executive of individual local representatives and/or programme chairmen. Consequently, it was moved that the executive be empowered to co-opt members if necessary from within or without the Society to serve as local representative and/or programme chairman for the C.S.R.S. Annual Meeting. The motion was carried. 


\section{6 / Renaissance and Reformation}

The Programme for 1982 Ottawa Meeting:

The Chairman announced that Don Beecher of Carleton University has agreed to be the local representative in Ottawa during 1982. Two joint sessions have been proposed: first, Judith Henderson and Josef Schmidt have suggested a joint session with the Canadian Seminar for the History of Rhetoric; second, Amilcare Iannucci suggested a joint session with Comparative Literature. Also, there have been requests that the format of the sessions be varied to include panel discussions, debates and communications. Five papers per session were judged to have been too onerous and a reduction of the size of the programme was proposed. There was general agreement on each of these items and they will be communicated to Don Beecher.

Finally, the executive, on behalf of the C.S.R.S., thanked the Reverend Professor Lawrence Murphy of St. Mary's University for serving as our local representative. Also, the Centre for Reformation and Renaissance Studies and especially its Curator, Konrad Eisenbichler, were thanked for their assistance in processing the mailings for the C.S.R.S. and for help in registration. 